\title{
Blood Eosinophilia and Its Stability in Hospitalized COPD Exacerbations are Associated with Lower Risk of All-Cause Mortality
}

This article was published in the following Dove Press journal: International Journal of Chronic Obstructive Pulmonary Disease

\author{
Ying Zhangl,* \\ Li-Rong Liang $\mathbb{( D}^{2, *}$ \\ Shu Zhang $\mathbb{D}^{\prime}$ \\ Yong Lu' \\ Yang-Yu Chen' \\ Huan-Zhong Shi' \\ Ying-Xiang Lin'
}

'Department of Respiratory and Critical Care Medicine, Beijing Institute of Respiratory Medicine and Beijing Chao-Yang Hospital, Capital Medical University, Beijing 100020, People's Republic of China; ${ }^{2}$ Clinical Epidemiology and Tobacco Dependence Treatment Research Department, Beijing Institute of Respiratory Medicine, Beijing ChaoYang Hospital, Capital Medical University, Beijing 100020, People's Republic of China

*These authors contributed equally to this work
Correspondence: Huan-Zhong Shi; Ying-Xiang Lin

Department of Respiratory and Critical

Care Medicine, Beijing Chao-Yang Hospital, Capital Medical University, 8 Gongti Nanlu, Chaoyang District, Beijing 100020, People's Republic of China $\mathrm{Tel} / \mathrm{Fax}+86$ I0 65935208

Email shihuanzhong@sina.com; bjlin666@I63.com
Purpose: Peripheral blood eosinophilic counts are susceptible to many factors and have variability over time. There are limited studies on association of blood eosinophilia with long-term mortality of chronic obstructive pulmonary disease (COPD) patients and these results remain controversial. Our aims were to explore the association of blood eosinophilia at index hospitalization and stability of blood eosinophilia stability over 5 years with all-cause mortality of patients hospitalized for acute exacerbation of COPD (AECOPD).

Patients and Methods: Eight hundred twenty-nine patients hospitalized for AECOPD between 2013 and 2014 were included in this study and grouped into two groups according to blood eosinophil with $150 \mathrm{cells} / \mu \mathrm{L}$ used as the cutoff value to form eosinophilic and noneosinophilic groups. Two hundred forty-one COPD inpatients with at least three blood eosinophils measured from different hospitalizations were used for analysis of longitudinally eosinophilic stability and divided into three groups according to the same cutoff value: predominantly (PE), intermittently (IE) and rarely (RE) eosinophilic groups. Cox regression analysis was used to determine the association of blood eosinophilia and all-cause mortality. Results: In patients hospitalized for AECOPD, 261 (31.5\%) at baseline and 41 (17\%) based on at least three measurements of blood eosinophils had increased blood eosinophils. For all-cause mortality, eosinophilic COPD patients at index hospitalization had a lower all-cause mortality compared with non-eosinophilic COPD patients (hazard ratio $0.77,95 \%$ confidence interval 0.6-0.99, $P=0.04$ ). In patients readmitted for AECOPD by longitudinal eosinophil stability, with the RE group used as reference, the PE group was associated with a lower all-cause mortality of AECOPD patients (hazard ratio 0.43 , 95\% confidence interval $0.22-0.85, P=0.016$ ), compared to the IE group (hazard ratio $0.72,95 \%$ confidence interval $0.47-1.11, P=0.133)$.

Conclusion: Patients with increased eosinophils (using eosinophil 150 cells $/ \mu \mathrm{L}$ as a cutoff value), especially predominantly increased eosinophil levels based on multiple measurements, had a lower risk of all-cause mortality. Blood eosinophilia can be used as a biomarker in hospitalized COPD exacerbations for predicting the risk of all-cause mortality.

Keywords: acute exacerbation, chronic obstructive pulmonary disease, blood eosinophilia, mortality

\section{Introduction}

Acute exacerbations of chronic obstructive pulmonary disease (AECOPD) are associated with high mortality and hospital readmission, ${ }^{1}$ and are heterogeneous with respect to etiology, response to therapy, and prognosis. Identification of special phenotypes in 
patients with AECOPD is necessary to establish personalized management for COPD patients.

Increased blood eosinophilic inflammation has been found in some stable and acute exacerbation COPD patients. $^{2-7}$ Eosinophilic COPD patients appear to be a subgroup of patients with specific clinical phenotype who present with better responsiveness to corticosteroid in preventing lung function decline and reducing the failure of COPD exacerbation treatment. ${ }^{8-10}$ These findings may suggest blood eosinophilia can be used as a potential prognostic marker for predicting the risk of mortality of COPD patients.

At present, the relationship between blood eosinophilia at index hospitalization and mortality of COPD patients is controversial. ${ }^{11-14}$ Further studies showed blood eosinophil counts were susceptible to many factors and had variability throughout the course of $\mathrm{COPD}^{15-20}$ and using only one measurement of blood eosinophil count may not be a reliable predictor of COPD clinical outcome. Presently, there is no general consensus on the cutoff value for categorizing blood eosinophils to guide management of COPD patients. Therefore, it is important to explore studies on the association of the stability of blood eosinophil counts over time and mortality of COPD patients. Some previous studies revealed that persistently increased blood eosinophil counts were associated with better survival of COPD patients, but study subjects were mainly concentrated in stable COPD patients. $15,18,19$ To date, there are very limited studies on the stability of increased blood eosinophils over time and its association with mortality of patients hospitalized for AECOPD.
Therefore, our aim was to assess the association of increased blood eosinophil counts at index hospitalization with all-cause mortality of patients hospitalized for AECOPD. Specifically, our aim was to explore the stability of blood eosinophil counts based on at least three measurements over 5 years and its association with allcause mortality of AECOPD inpatients.

\section{Methods \\ Study Subjects}

The patients first admitted for AECOPD at Beijing ChaoYang Hospital, in Beijing, People's Republic of China at the index hospitalization date from January 1, 2013, to December 31, 2014, were initially included in this study. The subject enrollment flow diagram is shown in Figure 1. COPD was diagnosed according to the Global Initiative for Chronic Obstructive Pulmonary Disease (GOLD) ${ }^{21}$ and specific inclusion criteria were as follows: all study subjects were 40 years of age or older; smoking history $\geq 10$ packyear or/and biomass history $\geq 10$ years and post bronchodilator forced expiratory volume in 1 second $\left(\mathrm{FEV}_{1}\right)$ /forced vital capacity (FVC)\% $<70 \%$; discharged alive; the blood eosinophil counts taken within 24 hours after the index hospitalization (including emergency room). The exclusion criteria were defined as follows: 1) active tumor; 2) asthmaCOPD overlap as discharged diagnosis, however patients with a history of asthma were not excluded; 3) other clinically relevant lung disease; and 4) patients lost to follow up.

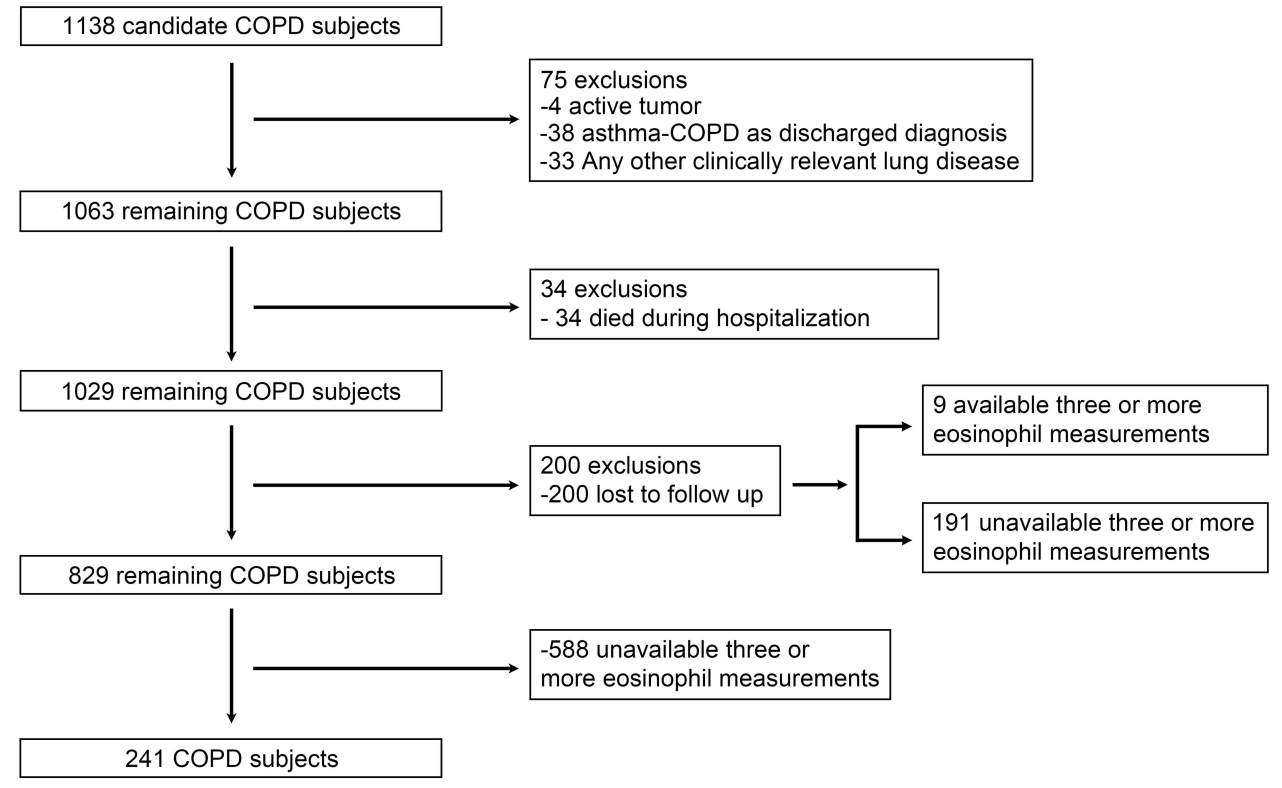

Figure I The subject enrollment flow diagram. 
Since AECOPD is mainly triggered by respiratory tract infections, we included patients with pneumonia. Therefore, 829 inpatients with primary discharged diagnosis of AECOPD were used for analysis of the association of blood eosinophils at baseline with all-cause mortality. In order to analyze the association of longitudinal stability of blood eosinophils and all-cause mortality, 241 inpatients who underwent at least three hospitalizations for AECOPD over 5 years and had available blood eosinophilic counts measured within 24 hours after each admission were selected. All data was collected from an inpatient electronic management system. This study was conducted in accordance with the Declaration of Helsinki. The research scheme was approved by the ethics committee of Beijing Chao-Yang Hospital (IRB No.2017-23). Informed consent from patients was waived because this study was observational, non-interventional and had no risk or harm to COPD patients. We declared that the patients' data were confidential and did not compromise the patients' interest.

\section{Definitions of Blood Eosinophils}

A pre-specified eosinophil cutoff value of 150 cells $/ \mu \mathrm{L}$ was used to characterize the study cohort and determine associations with clinical outcomes. ${ }^{19}$ The study subjects using 150 cells $/ \mu \mathrm{L}$ as the cutoff value of blood eosinophil counts were categorized as eosinophilic $(\geq 150$ cells $/ \mu \mathrm{L})$ and non-eosinophilic $(<150$ cells $/ \mu \mathrm{L})$ groups.

In order to investigate the fluctuation of blood eosinophils, 241 COPD patients underwent three to six blood eosinophil measurements over 5 years. A total of 165 patients had three available blood eosinophil results, 66 patients had four available blood eosinophils, nine patients had five available blood eosinophils and one patient had six available blood eosinophils. All the results of blood eosinophils were measured within 24 hours at each hospital admission. Each result of blood eosinophil counts came from different hospitalizations for AECOPD. For patients who had more than one hospitalization for AECOPD in 1 year, if the interval between hospitalizations was within 30 days, it was counted as one hospitalization and the first measured blood eosinophil count was used for analysis. COPD patients were divided into three groups according to 150 cells $/ \mu \mathrm{L}$ as the cutoff value of blood eosinophils: predominantly $(\mathrm{PE})$, intermittently (IE) and rarely (RE) eosinophilic groups. ${ }^{22}$ The PE group was defined as blood eosinophil counts $\geq 150$ cells $/ \mu \mathrm{L}$ measured within 24 hours at each hospitalization for AECOPD or the presence of blood eosinophil counts $<150$ cells/ $\mu \mathrm{L}$ occurred only once during multiple hospitalizations; the RE group was defined as blood eosinophil counts $<150$ cells $/ \mu \mathrm{L}$ measured within 24 hours at each hospitalization for AECOPD or the presence of blood eosinophil counts $\geq 150$ cells $/ \mu \mathrm{L}$ occurred only once during multiple hospitalizations; the IE group was defined when none of the above-mentioned criteria were met. However, the patients who had only three available blood eosinophil results were defined as the PE group if each blood eosinophil count was $\geq 150$ cells/ $\mu \mathrm{L}$ or as the RE group if each blood eosinophil count was $<150$ cells $/ \mu \mathrm{L}$, and the other patients were defined as the IE group.

\section{Study Variables and Outcomes}

All subjects' demographic characteristics (age, gender, height, weight, and smoking history), clinical symptoms (sputum, dyspnea), laboratory test (blood routine test, biochemistry), drug treatment during admission (antibiotic, inhaled corticosteroid (ICS) and intravenous corticosteroid administrations; intravenous corticosteroid was expressed as equivalent dose of oral prednisone), history of asthma and hospitalization for AECOPD in the previous year were collected. Comorbidity was quantified according to the Charlson Comorbidity Index. ${ }^{23}$

In addition, the primary outcome was all-cause mortality which was investigated by telephone contact and/or checking electronic medical record from January 1, 2013 to March 19, 2018. The telephone follow-up of all patients was completed from January 1, 2018 to March 19, 2018. The date of the last telephone contact for survival status was defined as the final date of outcome follow-up, which was March 19, 2018.

\section{Data Analysis}

Continuous variables were summarized as mean and standard deviation (SD), and categorical variables were summarized as absolute numbers and percentages. Comparison of categorical variables were performed using the chisquare test or Fisher's exact test. For continuous variables, Student's $t$-test or analysis of variance was done for data with normal distribution and the nonparametric test was done for data not showing normal distribution. The Kaplan-Meier analysis was performed to compare allcause mortality of patients with different blood eosinophilic levels. The Cox proportional hazards regression models were conducted to evaluate the association of blood eosinophil counts at baseline and longitudinal stability of blood eosinophil counts with the risk of all-cause mortality, 
respectively. In the Cox proportional hazards regression models, potential confounding factors were adjusted such as age (using $\geq 60$ years as cutoff value), hospitalization for AECOPD in the previous year, Charlson Comorbidity Index. A two-sided $P$-value $<0.05$ was considered statistically significant. All data were analyzed using IBM SPSS Statistics for Window, version 23.0 (SPSS, IBM Corporation, Armonk, NY, USA) and the R software (Version 3.6.1).

We also performed repeatedly the association analysis of baseline blood eosinophil and all-cause mortality of patients with at least three blood eosinophil counts measured at admission for AECOPD, as sensitivity analysis.

\section{Results}

\section{The Clinical Characteristics of Patients Hospitalized for AECOPD at Baseline}

We identified 829 AECOPD patients with blood eosinophil counts at baseline. These COPD patients were stratified into non-eosinophilic $(n=568)$ and eosinophilic $(n=261)$ groups according to 150 cells $/ \mu \mathrm{L}$ used as cutoff value of blood eosinophil counts. The baseline characteristics of 829 patients hospitalized for AECOPD are shown in Table 1. Compared with the non-eosinophilic group, the eosinophilic group tended to have a lower Charlson Comorbidity Index $(P<0.001)$, a shorter time since onset of symptoms $(P=0.021)$, a lower neutrophil fraction $(P<0.001)$, a lower proportion of intravenous corticosteroids treatments $(\mathrm{P}<0.001)$, a lower proportion of dual antibiotics treatments $(P=0.027)$ and a shorter length of stay $(P=0.002)$. In intravenous corticosteroid-treated patients, the eosinophilic group tended to have shorter days of intravenous corticosteroid treatment $(P=0.01)$ and lower total amount of intravenous corticosteroids treatment $(P=0.008)$ than the non-eosinophil group. For the usage of ICS during index hospitalization, there was no statistical difference between groups $(\mathrm{P}=0.965)$. There were no significant differences in other variables.

\section{Survival Analyses for Patients Hospitalized for AECOPD at Baseline}

The median follow-up (interquartile range) was 46 months (33-54). Overall, 312 (37.6\%) COPD patients died during the follow up. There was no statistical difference in specific cause of death between the two groups at baseline $(P=0.794)$ (Table 2).
Table I Baseline Characteristics and Outcomes of Patients Hospitalized for AECOPD According to Blood Eosinophil $\geq 150$ Cells/ $\mu \mathrm{L}$ as the Cutoff Value

\begin{tabular}{|c|c|c|c|}
\hline Variables & $\begin{array}{l}\text { Eosinophils } \\
\geq 150 \text { Cells/ } \mu \mathrm{L} \\
(\mathrm{N}=26 \mathrm{I})\end{array}$ & $\begin{array}{l}\text { Eosinophils } \\
<150 \text { Cells/ } \mu \mathrm{L} \\
(\mathrm{N}=568)\end{array}$ & $P$-value \\
\hline Male & $197(75.5)$ & $391(68.8)$ & 0.051 \\
\hline Age $\geq 60$ years & $235(90.0)$ & $507(89.3)$ & 0.734 \\
\hline Smoking history & $199(76.2)$ & $423(74.5)$ & 0.584 \\
\hline Pack-years & $41.25 \pm 26.36$ & $41.27 \pm 36.43$ & 0.363 \\
\hline $\mathrm{BMI}^{\mathrm{d}}, \mathrm{kg} / \mathrm{m}^{2}$ & $23.12 \pm 4.49$ & $23.45 \pm 4.48$ & 0.200 \\
\hline History of asthma & $20(7.7)$ & $49(8.6)$ & 0.641 \\
\hline \multicolumn{4}{|l|}{ Comorbidities } \\
\hline Systemic hypertension & $116(44.4)$ & $276(48.6)$ & 0.267 \\
\hline Cardiac artery disease & $53(20.3)$ & $138(24.3)$ & 0.205 \\
\hline Atrial fibrillation & $15(5.7)$ & $51(9.0)$ & 0.110 \\
\hline Congestive heart failure & $9(3.4)$ & $26(4.6)$ & 0.453 \\
\hline Diabetes & $48(18.4)$ & $122(2 \mid .5)$ & 0.306 \\
\hline Cerebrovascular disease & $22(8.4)$ & $53(9.3)$ & 0.674 \\
\hline Connective tissue disease & I (0.4) & $7(1.2)$ & 0.245 \\
\hline Liver disease & $2(0.8)$ & $5(0.9)$ & 0.868 \\
\hline Charlson Comorbidity & $1.61 \pm 0.85$ & $1.86 \pm 0.93$ & $<0.001$ \\
\hline Index & & & \\
\hline $\begin{array}{l}\text { Hospitalization for COPD in } \\
\text { the previous year }\end{array}$ & $92(35.2)$ & $207(36.4)$ & 0.739 \\
\hline $\begin{array}{l}\text { Time since onset of } \\
\text { symptoms, years }\end{array}$ & $16.31 \pm 14.92$ & $17.95 \pm 14.00$ & 0.021 \\
\hline Sputum During Admission & & & 0.150 \\
\hline None & $23(8.8)$ & $30(5.3)$ & \\
\hline White & $|6|(61.7)$ & $369(65)$ & \\
\hline Purulent & $77(29.5)$ & $169(29.8)$ & \\
\hline Dyspnea during admission & $254(97.3)$ & $559(98.4)$ & 0.286 \\
\hline \multicolumn{4}{|l|}{ Laboratory } \\
\hline WBC, $10^{9} / \mathrm{L}$ & $7.40 \pm 2.34$ & $8.09 \pm 3.60$ & 0.110 \\
\hline Neutrophil, \% & $64.53 \pm 10.48$ & $76.32 \pm 36.28$ & $<0.001$ \\
\hline Hemoglobin, $g / L$ & $|34.9| \pm 2 \mid .88$ & $132.28 \pm 20.45$ & 0.057 \\
\hline Albumin, $g / L$ & $33.25 \pm 4.1$ & $32.8 I \pm 4.5 I$ & 0.113 \\
\hline \multicolumn{4}{|l|}{$\begin{array}{l}\text { Drug Treatment During } \\
\text { Admission }\end{array}$} \\
\hline ICS & $194(74.3)$ & $423(74.5)$ & 0.965 \\
\hline IVS, & $60(23)$ & $204(35.9)$ & $<0.001$ \\
\hline Duration of IVS, days & $3.97 \pm 2.66$ & $5.04 \pm 3.31$ & 0.01 \\
\hline Total amount of IVS, mg & $204.17 \pm 154.4$ & $261.13 \pm 180.49$ & 0.008 \\
\hline Antibiotics & & & 0.027 \\
\hline None & $10(3.8)$ & $20(3.5)$ & $0.886^{\mathrm{a}}$ \\
\hline Single antibiotic & $|8|(69.3)$ & $342(60.2)$ & $0.007^{b}$ \\
\hline Dual antibiotics & $70(26.8)$ & $206(36.3)$ & $0.345^{c}$ \\
\hline Length of stay, days & $9[2-42]$ & $10[1-78]$ & 0.002 \\
\hline
\end{tabular}

Notes: Data are presented as no. (\%), mean \pm SD, or median [range]. ${ }^{a}$ Comparison between none and single antibiotic groups. ${ }^{\mathrm{C}}$ Comparison between none and dual antibiotics groups. ${ }^{\mathrm{b}}$ Comparison between single and dual antibiotics groups. ${ }^{\mathrm{d}} \mathrm{BMI}$ has 146 missing values. There are 26 (10\%) and 120 (21.1\%) missing values in the eosinophils $\geq 150$ cells/ $\mu \mathrm{L}$ group and eosinophils $<150$ cells $/ \mu \mathrm{L}$ group, respectively. Abbreviations: AECOPD, acute exacerbation of chronic obstructive pulmonary disease; BMI, body mass index; COPD, chronic obstructive pulmonary disease; WBC, white blood cell; ICS, inhaled corticosteroid; IVS, intravenous corticosteroid. 
Table 2 Comparisons of Overall and Specific Cause of Death Among Patients Hospitalized for AECOPD According to Blood Eosinophil $\geq 150$ Cells $/ \mu \mathrm{L}$ as the Cutoff Value

\begin{tabular}{|l|l|l|l|}
\hline Cause of Death & $\begin{array}{l}\text { Eosinophils } \\
\geq 150 \text { Cells/ } \boldsymbol{\mu L} \\
\mathbf{( N = 8 4 )}\end{array}$ & $\begin{array}{l}\text { Eosinophils } \\
<150 \text { Cells/ } \boldsymbol{\mu L} \\
(\mathbf{N}=\mathbf{2 2 8})\end{array}$ & P-value \\
\hline All causes & $84(32.2)$ & $228(40.1)$ & 0.028 \\
\hline Major Causes & & & 0.794 \\
Respiratory disease & $54(64.3)$ & $153(67.1)$ & \\
Cardiovascular disease & $8(9.5)$ & $\begin{array}{l}10.5) \\
23(10.1)\end{array}$ & \\
Cancer & $8(9.5)$ & $28(12.3)$ & \\
Other diseases & $14(16.7)$ & &
\end{tabular}

Note: Data are presented as no. (\%).

Abbreviation: AECOPD, acute exacerbation of chronic obstructive pulmonary disease.

The Kaplan-Meier survival curves between noneosinophilic and eosinophilic groups are shown in Figure 2. The eosinophilic group tended to have a lower risk of allcause mortality compared with the non-eosinophilic group $(P=0.023)$.

Table 3 shows Cox regression analysis for the association of increased eosinophils measured at index hospitalization with the risk of all-cause death among patients hospitalized for AECOPD. The unadjusted Cox regression analysis showed blood eosinophil $\geq 150$ cells $/ \mu \mathrm{L}$ was associated with lower risk of all-cause mortality (Hazard Ratio $[\mathrm{HR}]=0.75$, 95\% Confidence Interval [CI], 0.58-0.96, $P=0.025)$. The multi-adjusted Cox regression analysis showed the association remained unchanged after adjusting for age $\geq 60$ years, Charlson Comorbidity Index and hospitalization for COPD in the previous year $(\mathrm{HR}=0.77,95 \% \mathrm{CI}, 0.60-0.99$, $P=0.040$ ). When the association analysis was repeatedly performed using 200 cells $/ \mu \mathrm{L}$ as the cutoff value in the same model, blood eosinophils $\geq 200$ cells $/ \mu \mathrm{L}$ were associated with lower risk of all-cause mortality with borderline statistical significance $(\mathrm{HR}=0.76,95 \%$ CI, 0.58-1.01, $P=0.055$ ) (Supplementary Table A1).Once the cutoff value of blood eosinophil counts was raised to 300 cells $/ \mu \mathrm{L}$, the association did not reach statistical significance due to the relatively low number of patients above the cutoff value limiting the statistical power $(\mathrm{HR}=0.78,95 \% \mathrm{CI}, 0.55-1.10$, $P=0.153$ ) (Supplementary Table A2).

To control a selection bias from the missing data due to unavailability to follow up in the Cox regression analysis, 200 patients who were lost to follow up were defined as censoring data which were included in the same Cox regression model, as a sensitivity analysis. Supplementary Table A3 showed the association still remained statistically significant $(\mathrm{HR}=0.75$, 95\% CI, 0.59-0.97, $P=0.025$ ).

\section{Baseline Characteristics of Patients with Readmission by Longitudinal Eosinophil Stability}

We identified 241 AECOPD patients with at least three blood eosinophil counts. These COPD patients were stratified into rarely eosinophilic ( $R E, n=103$ ), intermittently eosinophilic (IE, $\mathrm{n}=97$ ), predominantly eosinophilic (PE, $\mathrm{n}=41$ ) groups according to 150 cells $/ \mu \mathrm{L}$ of blood eosinophil counts as the cutoff value (Table 4). Compared with other two groups, the PE group tended to have a higher proportion of male patients $(P=0.042)$ and a lower neutrophil fraction $(P=0.011)$. In intravenous corticosteroidtreated patients, the PE group tended to have shorter days of intravenous corticosteroid treatment $(P=0.014)$ and lower total amount of intravenous corticosteroid treatment $(P=0.023)$. For the usage of ICS at index hospitalization, there was no statistical significance among the three groups $(\mathrm{P}=0.797)$. There was no significant difference in other variables.

\section{Survival Analysis of Patients Readmitted for AECOPD by Longitudinal Eosinophil Stability}

The median follow-up (interquartile range) was 48 months (35-56), and 96 (39.8\%) COPD patients died during the follow up. There was no significant difference in specific cause of death among the three groups $(P=0.088)$ (Table 5).

The Kaplan-Meier survival curves showed the PE group tended to have a lower risk of all-cause mortality compared with the IE and RE groups ( $P=0.035$ ) (Figure 3 ).

Table 6 shows the Cox regression analysis for the association of predominantly high eosinophils with the risk of allcause death among patients readmitted for AECOPD. Utilizing the RE group as a reference point, the unadjusted Cox regression analysis revealed predominant eosinophils $\geq 150$ cells $/ \mu \mathrm{L}$ were associated with lower risk of all-cause mortality of COPD patients ( $\mathrm{HR}=0.44,95 \% \mathrm{CI}, 0.22-0.86$, $P=0.017)$ compared to intermittent eosinophils $\geq 150$ cells $/ \mu \mathrm{L}$ (HR $=0.73,95 \% \mathrm{CI}, 0.48-1.12, P=0.147)$. The multi-adjusted Cox regression analysis revealed predominant eosinophils $\geq 150 \mathrm{cells} / \mu \mathrm{L}$ were still associated with lower risk of allcause mortality of COPD patients (multi-adjusted HR 0.43, 95\% CI 0.22-0.85, $P=0.016$ ) compared to intermittent eosinophils $\geq 150$ cells $/ \mu \mathrm{L} \quad(\mathrm{HR}=0.72,95 \% \quad \mathrm{CI}, \quad 0.47-1.11$, $P=0.133)$ after adjusting for other variables. We repeatedly performed the analysis using 200 cells $/ \mu \mathrm{L}$ and 300 cells $/ \mu \mathrm{L}$ as 


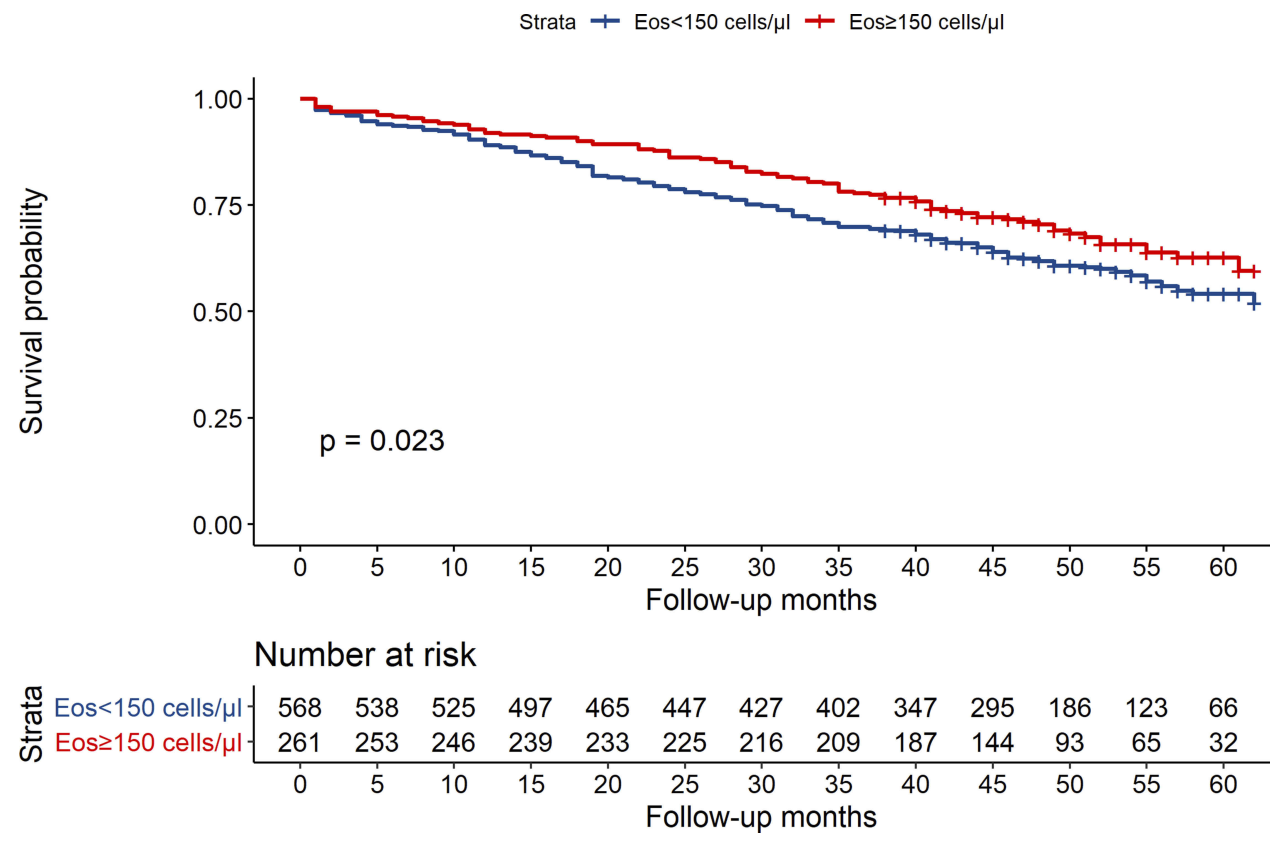

Figure 2 Kaplan-Maier survival curves for the groups, blood eosinophil (Eos) $\geq 150$ cells $/ \mu \mathrm{L}$ and blood eosinophil $($ Eos) $<150$ cells $/ \mu \mathrm{L}(P=0.023)$

the cutoff values in the same Cox regression model. However, it was no longer significant (Supplementary Tables A4, A5).

In order to control selective bias, nine missing patients who had three or more blood eosinophils were included in the same Cox regression model as a sensitivity analysis, Supplementary Table A6 showed predominantly high eosinophils $\geq 150$ cells $/ \mu \mathrm{L}$ was still independently associated with lower risk of all-cause death among patients readmitted for AECOPD $(\mathrm{HR}=0.43,95 \% \mathrm{CI}, 0.22-0.85, P=0.016)$.

\section{Sensitivity Analysis on the Association of Increased Eosinophils ( $\geq 150$ cells $/ \mu \mathrm{L}$ ) Measured at Baseline with the Risk of All- Cause Death Among Patients Readmitted for AECOPD}

When Cox regression analysis was used for the association of blood eosinophil measured at index admission for
AECOPD and all-cause mortality of patients with at least three blood eosinophil counts, increased blood eosinophil $\geq 150$ cells $/ \mu \mathrm{L}$ was no longer associated with lower risk of all-cause mortality (Supplementary Table A7).

\section{Discussion}

Our study subjects were based on inpatients with COPD exacerbation, which was different from the previous studies from stable COPD patients. Our findings predicted that when using 150 cells $/ \mu \mathrm{L}$ of blood eosinophil counts as cutoff value, increased blood eosinophils measured at index hospitalization was associated with lower risk of all-cause mortality in patients hospitalized for AECOPD. More importantly, predominantly increased eosinophils based on three or more measurements were still associated with lower all-cause mortality among patients readmitted for AECOPD by longitudinal eosinophil stability.

Table 3 The Association of Increased Eosinophils Measured at Index Hospitalization with the Risk of All-Cause Death Among Patients Hospitalized for AECOPD According to Cox Regression Analysis ( $N=829)$

\begin{tabular}{|l|l|l|l|l|}
\hline Variables & Unadjusted HR (95\% Cl) & P-value & Multi-Adjusted HR (95\% Cl) & P-value \\
\hline Age $\geq 60$ years & $2.15(1.33-3.46)$ & 0.002 & $2.15(1.34-3.47)$ & 0.002 \\
Eosinophils $(\geq 150$ cells $/ \mu \mathrm{L})$ & $0.75(0.58-0.96)$ & 0.025 & $0.77(0.60-0.99)$ & 0.040 \\
Charlson Comorbidity Index & $1.19(1.06-1.33)$ & 0.003 & $1.14(1.02-1.28)$ & 0.024 \\
Hospitalization for COPD in the previous year & $1.39(1.11-1.74)$ & 0.004 & $1.39(1.11-1.74)$ & 0.004 \\
\hline
\end{tabular}

Abbreviations: AECOPD, acute exacerbation of chronic obstructive pulmonary disease; COPD, chronic obstructive pulmonary disease. 
Table 4 Baseline Characteristics and Outcomes at the Index Hospitalization of Patients with Readmission by Longitudinal Eosinophil Stability ${ }^{\mathrm{a}}(\mathrm{N}=24 \mathrm{I})$

\begin{tabular}{|c|c|c|c|c|}
\hline Variables & $\begin{array}{l}\text { Rare Eosinophil } \geq 150 \\
\text { Cells/ } \mu \mathrm{L}(\mathrm{N}=103)\end{array}$ & $\begin{array}{l}\text { Intermittent } \\
\text { Eosinophil } \\
\geq \mathbf{I 5 0} \text { Cells/ } \mu \mathrm{L}(\mathrm{N}=97)\end{array}$ & $\begin{array}{l}\text { Predominant } \\
\text { Eosinophil } \\
\geq 150 \text { Cells/ } \mu \mathrm{L}(\mathrm{N}=4 \mathrm{I})\end{array}$ & $P$-value \\
\hline Male & 61 (59.2) & $67(69.1)$ & $33(80.5)$ & 0.042 \\
\hline Age $\geq 60$ years & 91 (88.3) & $90(92.8)$ & $38(92.7)$ & 0.502 \\
\hline Smoking history & 71 (68.9) & $75(77.3)$ & $35(85.4)$ & 0.097 \\
\hline Pack-years & $40.21 \pm 29.73$ & $39.5 I \pm 29.25$ & $42.04 \pm 22.86$ & 0.909 \\
\hline $\mathrm{BMI}^{\mathrm{b}}, \mathrm{kg} / \mathrm{m}^{2}$ & $23.05 \pm 5.1$ & $22.60 \pm 5.21$ & $22.86 \pm 5.60$ & 0.733 \\
\hline History of asthma & $9(8.7)$ & $9(9.3)$ & $5(12.2)$ & 0.811 \\
\hline \multicolumn{5}{|l|}{ Comorbidities } \\
\hline Systemic hypertension & $50(48.5)$ & $47(48.5)$ & $17(4 \mid .5)$ & 0.713 \\
\hline Cardiac artery disease & $28(27.2)$ & $24(24.7)$ & $6(14.6)$ & 0.277 \\
\hline Atrial fibrillation & $5(4.9)$ & $5(5.2)$ & $5(12.2)$ & 0.22 \\
\hline Congestive heart failure & $7(6.8)$ & $4(4.1)$ & I (2.4) & 0.490 \\
\hline Diabetes & $21(20.4)$ & $17(17.5)$ & $9(22.0)$ & 0.799 \\
\hline Cerebrovascular disease & $12(11.7)$ & $6(6.2)$ & $2(4.9)$ & 0.257 \\
\hline Connective tissue disease & $2(1.9)$ & $2(2.1)$ & $0(0)$ & 0.658 \\
\hline Liver disease & $2(1.9)$ & I (I.0) & I (2.4) & 0.803 \\
\hline Charlson Comorbidity Index & $1.98 \pm 1.08$ & $1.7 \pm 0.93$ & $1.73 \pm 0.92$ & 0.127 \\
\hline Hospitalization for COPD in the previous year & $55(53.4)$ & $52(53.6)$ & $21(5 \mid .2)$ & 0.965 \\
\hline Time since onset of symptoms, years & $18.56 \pm 14.9$ & $18.24 \pm 13.69$ & $18.76 \pm 13.30$ & 0.925 \\
\hline Sputum During Admission & & & & 0.945 \\
\hline None & $4(3.9)$ & $5(5.2)$ & I (2.4) & \\
\hline White & $64(62.1)$ & $57(58.8)$ & $26(63.4)$ & \\
\hline Purulent & $35(34)$ & $35(36.1)$ & $14(34.1)$ & \\
\hline Dyspnea during admission & $103(100)$ & $96(99)$ & $40(97.6)$ & 0.333 \\
\hline \multicolumn{5}{|l|}{ Laboratory } \\
\hline WBC $\times 109 / L$ & $8.12 \pm 3.6$ & $7.59 \pm 2.98$ & $7.5 \pm 2.49$ & 0.591 \\
\hline Neutrophil, \% & $73.78 \pm 11.86$ & $72.15 \pm 11.44$ & $67.82 \pm 10.28$ & 0.011 \\
\hline Hemoglobin, $g / L$ & $136.4 \pm 21.77$ & $131.18 \pm 20.45$ & $133.06 \pm 15.34$ & 0.207 \\
\hline Albumin, $g / L$ & $33.57 \pm 4.26$ & $32.86 \pm 4.29$ & $32.43 \pm 3.52$ & 0.314 \\
\hline \multicolumn{5}{|l|}{ Drug Treatment During Admission } \\
\hline ICS & $80(77.7)$ & $78(80.4)$ & $31(75.6)$ & 0.797 \\
\hline IVS & $44(42.7)$ & $33(34)$ & II (26.8) & 0.163 \\
\hline Duration of IVS, days & $4.73 \pm 3.25$ & $5.49 \pm 3.02$ & $2.82 \pm 2.04$ & 0.014 \\
\hline Total amount of IVS, mg & $254.55 \pm 204.55$ & $290.3 \pm 195.44$ & $145.46 \pm 105.96$ & 0.023 \\
\hline Antibiotics & & & & 0.079 \\
\hline None & $0(0)$ & $0(0)$ & I (2.4) & \\
\hline Single antibiotic & $58(56.3)$ & $65(67)$ & $28(68.3)$ & \\
\hline Dual antibiotics & $45(43.7)$ & $32(33)$ & $12(29.3)$ & \\
\hline Length of stay, days & $10[4-78]$ & $9[4-34]$ & $8[5-42]$ & 0.055 \\
\hline
\end{tabular}

Notes: Data are presented as no. (\%), mean \pm SD, or median [range]. ${ }^{a}$ Longitudinal eosinophil stability denotes prevalence of increased and low blood eosinophils over time. ${ }^{\mathrm{b}} \mathrm{BMI}$ has 13 missing values. There are $4(3.9 \%), 7$ (7.2\%) and 2 (4.9\%) missing values in rare eosinophil $\geq 150$ cells/ $\mu \mathrm{L}$ group, intermittent eosinophil $\geq 150$ cells/ $\mu \mathrm{L}$ group and predominant eosinophil $\geq 150$ cells/ $\mu \mathrm{L}$ group, respectively.

Abbreviations: BMI, body mass index; WBC, white blood cell; COPD, chronic obstructive pulmonary disease; WBC, white blood cell; ICS, inhaled corticosteroid; IVS, intravenous corticosteroid. 
Table 5 Comparison of Overall and Specific Cause of Death Among Patients Readmitted for AECOPD by Longitudinal Eosinophil Stability ${ }^{\mathrm{a}}$

\begin{tabular}{|c|c|c|c|c|}
\hline Cause of Death & $\begin{array}{l}\text { Rare Eosinophil } \\
\geq 150 \text { Cells/ } \mu \mathrm{L}(\mathrm{N}=49)\end{array}$ & $\begin{array}{l}\text { Intermittent Eosinophil } \\
\geq 150 \text { Cells } / \mu \mathrm{L}(\mathrm{N}=37)\end{array}$ & $\begin{array}{l}\text { Predominant Eosinophil } \\
\geq 150 \text { Cells } / \mu \mathrm{L}(\mathrm{N}=10)\end{array}$ & $P$-value \\
\hline All causes & $49(47.6)$ & $37(38.1)$ & $10(24.4)$ & 0.034 \\
\hline Major Causes & & & & 0.088 \\
\hline Respiratory disease & 35 (7I.4) & $30(8 I . I)$ & $4(40)$ & \\
\hline Cardiovascular disease & $5(10.2)$ & $5(13.5)$ & $2(20)$ & \\
\hline Cancer & $7(14.3)$ & I (2.7) & $2(20)$ & \\
\hline Other diseases & $2(4.1)$ & I (2.7) & $2(20)$ & \\
\hline
\end{tabular}

Notes: Data are presented as no. (\%). ${ }^{a}$ Longitudinal eosinophil stability denotes that prevalence of increased and low blood eosinophils over time. Abbreviation: AECOPD, acute exacerbation of chronic obstructive pulmonary disease.

Eosinophilic inflammation was thought to be a characteristic of asthma and has been found to be present in some COPD patients. Up to now, there is still no clear agreement as to the most appropriate cutoff value used for categorizing blood eosinophils. In some previous studies of COPD patients, a $2 \%$ cutoff value of blood eosinophil counts is generally used. ${ }^{4,5,24}$ Using 150 cells/ $\mu \mathrm{L}$ as a cutoff value showed a similar pattern of differences to $2 \%$ of blood eosinophils as a cutoff value. The correlation strength reached 0.88 between samples classification using $2 \%$ and 150 cells $/ \mu \mathrm{L}$ as cutoff values $(P<0.001){ }^{2}$ Therefore, it is reasonable to use absolute numbers $\geq 150$ cells $/ \mu \mathrm{L}$ as an alternative measure to the $2 \%$ eosinophil cutoff.

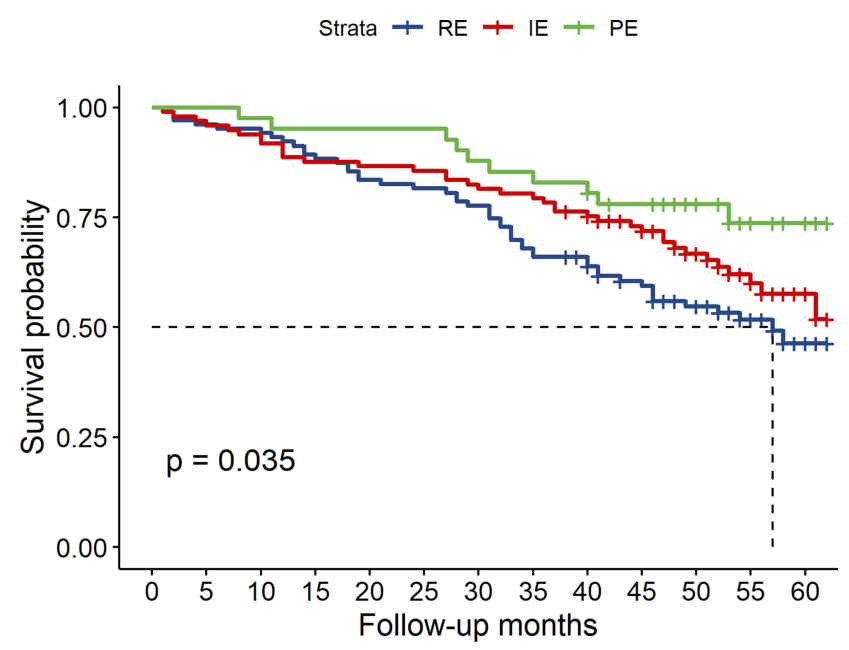

Number at risk

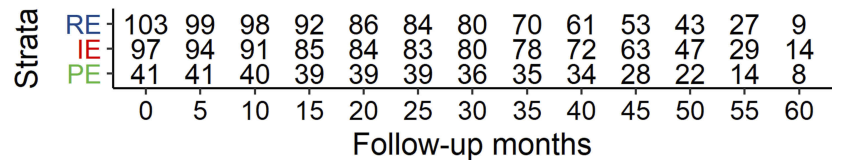

Figure 3 Kaplan-Maier survival curves for the groups, rare eosinophilic (RE), intermittently eosinophilic (IE) and predominantly eosinophilic (PE) $(P=0.035)$.
Furthermore, a relative percentage of total leukocyte count as a cutoff value of blood eosinophils was thought to be less reliable compared with using absolute blood eosinophil count. $^{25}$ The Global Initiative for Obstructive Lung Disease (GOLD) 2020 recommends a cutoff of 300 cells/ $\mu \mathrm{L}$ for the escalation and de-escalation of inhaled corticosteroids among patients with COPD. The previous study showed the prevalence of increased blood eosinophil counts may be lower in COPD exacerbations than in stable periods. ${ }^{20}$ We also found only $13.9 \%$ patients hospitalized for AECOPD in this study had blood eosinophil counts above 300 cells $/ \mu \mathrm{L}$ at index hospitalization. Thomas et $\mathrm{al}^{26}$ also proposed that using lower eosinophilic cutoff values (100 or 150 cells $/ \mu \mathrm{L}$ ) was more beneficial for investigation of the stability of blood eosinophil counts over time. Therefore, 150 cells $/ \mu \mathrm{L}$ was selected as the cutoff value of blood eosinophils in our study.

In our study, $31.5 \%$ patients hospitalized for AECOPD had increased blood eosinophilic counts $\geq 150$ cells $/ \mu \mathrm{L}$ at index hospitalization. These patients presented with fewer comorbidities, lower neutrophil fraction, shorter time since onset of symptoms and length of stay, which was similar to some previous studies. ${ }^{4,27}$ The corticosteroids and antibiotics are two classes of medications commonly used for COPD exacerbations, AECOPD patients are heterogeneous with respect to response to pharmacologic therapies. In the present study, any case decision to treatment of intravenous corticosteroids was based on clinical practice methods other than blood eosinophil status. This study revealed eosinophilic COPD patients had a lower proportion of intravenous corticosteroids administration. For those patients administered intravenous corticosteroids, eosinophilic COPD patients had a significantly shorter course and lower consumption of intravenous corticosteroid relative to noneosinophilic COPD patients. These results in our study 
Table 6 The Association of Predominant Eosinophilia with the Risk of All-Cause Death Among Patients Readmitted for AECOPD According to Cox Regression Analysis

\begin{tabular}{|l|l|l|l|l|}
\hline Variables & Unadjusted HR (95\% Cl) & P-value & Multi-Adjusted HR (95\% Cl) & P-value \\
\hline Age $\geq 60$ years & $2.70(0.99-7.34)$ & 0.052 & $2.92(1.07-7.98)$ & 0.036 \\
\hline Eosinophils $\geq 150$ cells/ L & & & & \\
$\quad$ Rare eosinophilia & Reference & & Reference \\
Intermittent eosinophilia & $0.73(0.48-1.12)$ & 0.147 & $0.72(0.47-1.11)$ & 0.133 \\
Predominant eosinophilia & $0.44(0.22-0.86)$ & 0.017 & $0.43(0.22-0.85)$ & 0.016 \\
P trend & & 0.040 & & 0.037 \\
\hline Charlson Comorbidity Index & $1.17(0.99-1.39)$ & 0.072 & $1.13(0.95-1.35)$ & 0.174 \\
Hospitalization for COPD in the previous year & $1.60(I .05-2.43)$ & 0.028 & $1.53(1.01-2.33)$ & 0.047 \\
\hline
\end{tabular}

Abbreviations: AECOPD, acute exacerbation of chronic obstructive pulmonary disease; COPD, chronic obstructive pulmonary disease.

showed COPD inpatients with high eosinophils presented with a better response to intravenous corticosteroids treatment, which were consistent with some previous studies. ${ }^{4,7,9,10}$ However, there was no significant difference between groups in inhaled corticosteroids during index admission. COPD exacerbations are mainly triggered by respiratory tract infection. Our study showed eosinophilic COPD patients had a lower proportion of dual antibiotic treatment compared with non-eosinophilic COPD patients, which may further suggest eosinophilic COPD patients may have mild bacterial infection. These data may predict a lower risk of all-cause mortality among eosinophilic COPD patients.

During the median follow-up of 46 months, 312 patients hospitalized for COPD died in the period of follow-up. Blood eosinophils $\geq 150$ cells $/ \mu \mathrm{L}$ measured at baseline were associated with lower risk of all-cause mortality among patients hospitalized for COPD exacerbations (this trend persisted after excluding patients with a history of asthma, see Supplementary Table A8). We also repeated these analyses using 200 cells $/ \mu \mathrm{L}$ and 300 cells $/ \mu \mathrm{L}$ as cutoff values of blood eosinophils. Blood eosinophils $\geq 200$ cells/ $\mu \mathrm{L}$ were associated with lower risk of all-cause death with borderline statistical significance $(P=0.055)$, while it was no longer significant when $300 \mathrm{cells} / \mu \mathrm{L}$ was used as the cutoff value of blood eosinophil. It may be related to a relatively low percentage of higher blood eosinophil counts in this study. Otherwise, we compute interquartile levels of blood eosinophil counts and put the variables of interquartile levels of blood eosinophil counts into the same Cox regression model. We repeated the association analysis and observed that with the 1st interquartile level as reference group, the risk of death at the $2 \mathrm{nd}, 3 \mathrm{rd}$, and 4 th interquartile levels gradually decreased and the linear trend reached to statistical significance (Supplementary Table A9). The sensitivity analysis indicated that the higher the blood eosinophil counts, the lower the risk of all-cause death. Some previous studies also showed similar results. ${ }^{5,11-13}$ However, another study from France revealed there was no association of increased blood eosinophils and mortality of COPD patients regardless of the cutoff values. ${ }^{14}$ There might be some reasons which can explain these discrepancies: most importantly, blood eosinophils naturally fluctuate over time and are affected by many factors. Furthermore, selective differences in the cutoff values of blood eosinophils may affect the final results. Another point to consider is the difference of recruited study subjects' illness severity. The study subjects from our study and $\mathrm{Li}$ et $\mathrm{al}^{13}$ were patients hospitalized for AECOPD, Salturk et $\mathrm{al}^{5}$ study subjects were patients who were admitted to ICU with acute respiratory failure, while other studies' subjects were from stable COPD patients. ${ }^{11,12,14}$ In addition, whether patients suffering with asthma were included or not may affect study results.

Considering that blood eosinophil counts are significantly variable over time, a single measurement may not be a reliable predictor for mortality of COPD patients. Some studies have shown the association of stability of blood eosinophils over time with mortality of COPD patients. ${ }^{15,18,19}$ However, these study subjects were mainly concentrated on stable COPD patients. There are limited studies on the association of longitudinally eosinophilic stability with all-cause mortality of patients frequently hospitalized for AECOPD. In our study of hospitalized patients with COPD, 17\% had predominantly high eosinophils and had lower all-cause mortality compared to those 
with rare blood eosinophils $\geq 150$ cells $/ \mu \mathrm{L}$ (the result remained unchanged after excluding patients with a history of asthma, see Supplementary Table A10). This finding was consistent with those from previous studies from stable COPD patients. ${ }^{15,18,19}$ However, no statistically significant association was observed when using 200 cells $/ \mu \mathrm{L}$ or 300 cells $/ \mu \mathrm{L}$ as the cutoff values of blood eosinophils. This was due to the few number of patients with blood eosinophils $\geq 200$ cells $/ \mu \mathrm{L}$ and even fewer patients with blood eosinophils $\geq 300$ cells $/ \mu \mathrm{L}$ which limited the statistical power. This needs to be further confirmed by a large scale cohort study.

Our study suggested patients with increased eosinophils had a lower risk of all-cause mortality. It is well known that COPD patients with increased eosinophils present with better responsiveness to ICS. Therefore, this reduction in all-cause mortality among patients with increased blood eosinophil counts may be as a result of exposure to inhaled corticosteroids. Accordingly, we made further analysis adjusting for inhaled corticosteroids usage during index hospitalization in a Cox regression model, and the association analysis remained significant (Supplementary Table A11, A12). However, since we did not collect medication after index hospitalization, it is unknown what impact inhaled corticosteroids have on long-term mortality of stable COPD patients. Further studies are needed to confirm it.

In our study, we also performed repeated analysis for an association of baseline blood eosinophil $\geq 150$ cells $/ \mu \mathrm{L}$ and allcause mortality of patients with at least three blood eosinophil counts measured at admission for AECOPD. There was no statistical difference in mortality of COPD between the noneosinophilic and eosinophilic groups, which may be related to a change in the sample size of the database. For this small database, longitudinal stability of blood eosinophils used to predict all-cause mortality of COPD patients was superior to a single measurement of baseline blood eosinophils.

There were some strengths. COPD exacerbations are heterogeneous and blood eosinophils have variability, we chose patients hospitalized for AECOPD as the study subjects and analyzed blood eosinophil levels from subjects' subsequent hospitalizations. To our surprise, increased eosinophils (using lower eosinophils 150 cells/ $\mu \mathrm{L}$ as cutoff value) at index hospitalization or blood eosinophil longitudinal pattern over 5 years were associated with lower risk of all-cause mortality of patients hospitalized for AECOPD, which was different from those studies from stable COPD patients. Moreover, this study was from "real life" nature and not any intervention, therefore, it was more beneficial to clinical management of
COPD patients. However, there were some limitations. Because pre-hospitalization medication use was unavailable, it was difficult to rule out the impact of pre-hospitalization corticosteroid administration on blood eosinophil counts, which may be the result of the relatively lower prevalence of increased blood eosinophil counts. Secondly, due to the nature of retrospective studies, some confounding variables such as pulmonary function test, MRC dyspnea score, medication treatment after index discharge were also unavailable and thus were not analyzed in our study, which might bias our results to some extent. Another study limitation is that it was a single-center study of patients hospitalized for AECOPD in the People's Republic of China, therefore, the results may not be generalizable to the entire Chinese COPD population. Further multicenter studies of the Chinese population are very necessary to confirm these results.

\section{Conclusion}

These data suggested that patients with increased eosinophils (using lower eosinophil 150 cells $/ \mu \mathrm{L}$ as the cutoff value), especially predominantly increased eosinophil levels based on multiple measurements, had a lower risk of all-cause mortality. Blood eosinophilia can be used as a biomarker in hospitalized COPD exacerbations for predicting all-cause mortality.

\section{Funding}

This work was supported by the National Key R\&D Program of China (2016YFC1303900), the Beijing Municipal Administration of Hospitals' Mission Plan, the People's Republic of China (No. SML20150301), Capital's Funds for Health Improvement and Research (No. CFH20164-1062) and Chinese Medical Association Chronic Respiratory Disease Fund (No. CRD 08020440122).

\section{Disclosure}

Ying Zhang's present address: Department of Respiratory and Critical Care Medicine, Cangzhou Central Hospital, Cangzhou, Hebei 061000, China. Ying Zhang and Li-Rong are co-first authors. The authors report no conflicts of interest in this work.

\section{References}

1. Steer J, Gibson GJ, Bourke SC. Predicting outcomes following hospitalization for acute exacerbations of COPD. QJM. 2010;103 (11):817-829. doi:10.1093/qjmed/hcq126

2. Singh D, Kolsum U, Brightling CE, et al. Eosinophilic inflammation in COPD: prevalence and clinical characteristics. Eur Respir J. 2014;44 (6):1697-1700. doi:10.1183/09031936.00162414 
3. Negewo NA, McDonald VM, Baines KJ, et al. Peripheral blood eosinophils: a surrogate marker for airway eosinophilia in stable COPD. Int J Chron Obstruct Pulmon Dis. 2016;11:1495-1504. doi:10.2147/COPD.S100338

4. Serafino-Agrusa L, Scichilone N, Spatafora M, Battaglia S. Blood eosinophils and treatment response in hospitalized exacerbations of chronic obstructive pulmonary disease: a case-control study. Pulm Pharmacol Ther. 2016;37:89-94. doi:10.1016/j.pupt.2016.03.004

5. Saltürk C, Karakurt Z, Adiguzel N, Kargin F, Sari R, Celik ME. Does eosinophilic COPD exacerbation have a better patient outcome than non-eosinophilic in the intensive care unit? Int $J$ Chron Obstruct Pulmon Dis. 2015;10:1837-1846. doi:10.2147/COPD.S88058

6. Couillard S, Larivée P, Courteau J, Vanasse A. Eosinophils in COPD exacerbations are associated with increased readmissions. Chest. 2017;151(2):366-373. doi:10.1016/j.chest.2016.10.003

7. Bafadhel M, Greening NJ, Harvey-Dunstan TC, et al. Blood eosinophils and outcomes in severe hospitalized exacerbations of COPD. Chest. 2016;150(2):320-328. doi:10.1016/j.chest.2016.01.026

8. Barnes NC, Sharma R, Lettis S, Calverley PM. Blood eosinophils as a marker of response to inhaled corticosteroids in COPD. Eur Respir $J$. 2016;47(5):1374-1382. doi:10.1183/13993003.01370-2015

9. Bafadhel M, McKenna S, Terry S, et al. Blood eosinophils to direct corticosteroid treatment of exacerbations of chronic obstructive pulmonary disease: a randomized placebo-controlled trial. Am J Respir Crit Care Med. 2012;186(1):48-55. doi:10.1164/rccm.201108-1553OC

10. Bafadhel M, Davies L, Calverley PM, Aaron SD, Brightling CE, Pavord ID. Blood eosinophil guided prednisolone therapy for exacerbations of COPD: a further analysis. Eur Respir J. 2014;44 (3):789-791. doi:10.1183/09031936.00062614

11. Oh YM, Lee KS, Hong Y, et al. Blood eosinophil count as a prognostic biomarker in COPD. Int J Chron Obstruct Pulmon Dis. 2018;13:3589-3596. doi:10.2147/COPD.S179734

12. Mendy A, Forno E, Niyonsenga T, Gasana J. Blood biomarkers as predictors of long-term mortality in COPD. Clin Respir J. 2018;12 (5):1891-1899. doi:10.1111/crj.12752

13. Li Q, Larivée P, Courteau J, et al. Greater eosinophil counts at first COPD hospitalization are associated with more readmissions and fewer deaths. Int J Chron Obstruct Pulmon Dis. 2019;14:331-341. doi:10.2147/COPD.S187375

14. Zysman M, Deslee G, Caillaud D, et al. Relationship between blood eosinophils, clinical characteristics, and mortality in patients with COPD. Int J Chron Obstruct Pulmon Dis. 2017;12:1819-1824. doi:10.2147/COPD.S129787

15. Casanova C, Celli BR, de-Torres JP, et al. Prevalence of persistent blood eosinophilia: relation to outcomes in patients with COPD. Eur Respir J. 2017;50(5):1701162. doi:10.1183/13993003.01162-2017
16. Greulich T, Mager S, Lucke T, et al. Longitudinal stability of blood eosinophil count strata in the COPD COSYCONET cohort. Int J Chron Obstruct Pulmon Dis. 2018;13:2999-3002. doi:10.2147/COPD.S165909

17. Oshagbemi OA, Burden AM, Braeken DCW, et al. Stability of blood eosinophils in patients with chronic obstructive pulmonary disease and in control subjects, and the impact of sex, age, smoking, and baseline counts. Am J Respir Crit Care Med. 2017;195(10):1402-1404. doi:10.1164/rccm.201701-0009LE

18. Shin SH, Park HY, Kang D, et al. Serial blood eosinophils and clinical outcome in patients with chronic obstructive pulmonary disease. Respir Res. 2018;19(1):134. doi:10.1186/s12931-018-0840-x

19. Turato G, Semenzato U, Bazzan E, et al. Blood eosinophilia neither reflects tissue eosinophils nor worsens clinical outcomes in chronic obstructive pulmonary disease. Am J Respir Crit Care Med. 2018;197 (9):1216-1219. doi:10.1164/rccm.201708-1684LE

20. Schumann DM, Tamm M, Kostikas K, Stolz D. Stability of the blood eosinophilic phenotype in stable and exacerbated COPD. Chest. 2019;156(3):456-465. doi:10.1016/j.chest.2019.04.012

21. Vogelmeier CF, Criner GJ, Martinez FJ, et al. Global strategy for the diagnosis, management, and prevention of chronic obstructive lung disease 2017 report. Gold executive summary. Am J Respir Crit Care Med. 2017;195(5):557-582. doi:10.1164/rccm.201701-0218PP

22. Kim VL, Coombs NA, Staples KJ, et al. Impact and associations of eosinophilic inflammation in COPD: analysis of the AERIS cohort. Eur Respir J. 2017;50(4):1700853. doi:10.1183/13993003.00853-2017

23. Charlson ME, Pompei P, Ales KL, MacKenzie CR. A new method of classifying prognostic comorbidity in longitudinal studies: development and validation. $J$ Chronic Dis. 1987;40(5):373-383. doi:10.1016/0021-9681(87)90171-8

24. Pavord ID, Lettis S, Anzueto A, Barnes N. Blood eosinophil count and pneumonia risk in patients with chronic obstructive pulmonary disease: a patient-level meta-analysis. Lancet Respir Med. 2016;4 (9):731-741. doi:10.1016/S2213-2600(16)30148-5

25. Wedzicha JA. Eosinophils as biomarkers of chronic obstructive pulmonary disease exacerbation risk. maybe just for some? Am J Respir Crit Care Med. 2016;193(9):937-938. doi:10.1164/rccm.201601$0015 \mathrm{ED}$

26. Southworth T, Beech G, Foden P, Kolsum U, Singh D. The reproducibility of COPD blood eosinophil counts. Eur Respir J. 2018;52 (1):1800427. doi:10.1183/13993003.00427-2018

27. DiSantostefano RL, Hinds D, Le HV, Barnes NC. Relationship between blood eosinophils and clinical characteristics in a cross-sectional study of a US population-based COPD cohort. Respir Med. 2016;112:88-96. doi:10.1016/j.rmed.2016.01.013 


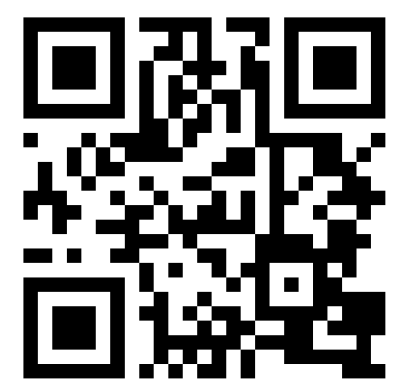

Point your SmartPhone at the code above. If you have a QR code reader the video abstract will appear. Or use: https://youtu.be/RroTKw3Hisg

\section{Publish your work in this journal}

The International Journal of COPD is an international, peer-reviewed journal of therapeutics and pharmacology focusing on concise rapid reporting of clinical studies and reviews in COPD. Special focus is given to the pathophysiological processes underlying the disease, intervention programs, patient focused education, and self management protocols. This journal is indexed on PubMed Central, MedLine and CAS. The manuscript management system is completely online and includes a very quick and fair peer-review system, which is all easy to use. Visit http://www.dovepress.com/testimonials.php to read real quotes from published authors. 